\title{
KINETIC ANALYSIS OF SECONDARY PRECIPITATION IN A HP40-Nb ALLOY
}

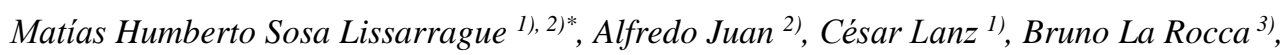 \\ Alberto Picasso ${ }^{1,4)}$ \\ 1) Laboratorio de Metalurgia Tecnología Mecánica, Universidad Nacional del Sur, \\ Departamento de Ingeniería, Av. L. N. Alem 1253, B8000CPB, Bahía Blanca, Argentina \\ ${ }^{2}$ )IFISUR, Universidad Nacional del Sur, CONICET, Departamento de Física - UNS, Av. L. N. \\ Alem 1253, B8000CPB, Bahía Blanca, Argentina \\ ${ }^{3}$ ) Becario del Consejo Interuniversitario Nacional (CIN) \\ ${ }^{4}$ ) Comisión de Investigaciones Cientificas de la Provincia de Buenos Aires (CICPBA), Calle 526 \\ entre 10 y 11, B1900, La Plata, Argentina
}

Received: 30.09.2019

Accepted: 27.11.2019

${ }^{*}$ Corresponding author: e-mail: mhsl1986@gmail.com, Tel.: +54 0291 4595179, Laboratorio de Metalurgia y Tecnología Mecánica, Universidad Nacional del Sur, Departamento de Ingeniería, Av. L. N. Alem 1253, B8000CPB, Bahía Blanca, Argentina

\begin{abstract}
The HP40-Nb heat resistant alloy (35Ni-25Cr-Nb) was analysed by means of optical microscopy after aging treatments at 1073 and $1173 \mathrm{~K}$ for different times, in order to apply the classic Johnson - Mehl - Avrami - Kolmogorov kinetic model (JMAK), and thus calculate the activation energy of secondary $\mathrm{M}_{23} \mathrm{C}_{6}$ precipitation, which occurs during thermal aging. The relevance of this theoretical analysis is to infer the mechanism that controls the nucleation and growth of $\mathrm{M}_{23} \mathrm{C}_{6}$ secondary carbides, since the amount and morphology of these phase influences the mechanical properties as well as the corrosion resistance in service. After performing the kinetic analysis using the JMAK model, the activation energy was found to be $208 \mathrm{~kJ} / \mathrm{mol}$, which would indicate that the secondary precipitation in this alloy is controlled by the Cr-diffusion phenomenon along the austenitic matrix.
\end{abstract}

Keywords: JMAK model, HP40-Nb, activation energy, $\mathrm{M}_{23} \mathrm{C}_{6}$ secondary carbide precipitation

\section{Introduction}

The HP40-Nb heat resistant alloy is widely used in pyrolysis furnaces due to its high corrosion resistance under high temperature service, which normally varies between 973 and $1273 \mathrm{~K}$. The high content of alloy elements such as chromium and nickel, give it corrosion resistance under aggressive atmospheres during service. These alloys are manufactured by centrifugal casting, resulting in a dendritic-type microstructure due to the high solidification rate of the alloy during its manufacturing process. The austenitic matrix rich in nickel, chromium and iron, is strengthened by a network of primary carbides that increases its mechanical strength [1-11]. It is during the exposure of the alloy at high temperatures that precipitation of secondary Cr-rich carbides of $\mathrm{M}_{23} \mathrm{C}_{6}$ type occurs, whose nuclei begin to form in the vicinity of the primary eutectic Cr-rich $\mathrm{M}_{23} \mathrm{C}_{6}$ carbides and $\mathrm{Nb}$-rich $\mathrm{MC}$ carbides network [7, 9, 12, 13]. Some authors have found for this heat resistant alloy that, in the as-cast condition, the primary carbides network is formed by $\mathrm{Cr}$-rich $\mathrm{M}_{7} \mathrm{C}_{3}$ and $\mathrm{Nb}$-rich $\mathrm{MC}$ carbides. Moreover, they have found that primary $\mathrm{Cr}$-rich $\mathrm{M}_{7} \mathrm{C}_{3}$ carbides remains unalterable during aging $[12,14,15] . \mathrm{M}_{23} \mathrm{C}_{6} \mathrm{Cr}$-rich secondary precipitation 
increases mechanical strength of the alloy when it operates at high temperatures that are characteristic of the pyrolysis production process. In this way, the mechanical properties are influenced by the volume fraction of secondary precipitation as well as its morphology and distribution along the matrix. However, excessive secondary precipitation leads on chromium depleted zones adjacent to the primary eutectic carbides network, since secondary precipitation causes chromium consumption in these areas, resulting in a decrease in resistance to oxidation at high temperature. Therefore, it is interesting to analyse the mechanism of precipitation, by kinetic models as the proposed by Johnson, Mehl, Avrami and Kolmogorov (JMAK model), that is widely used in the kinetic study of nucleation and growth reactions [10, 16-19]. In the present research work, it was found that the calculated activation energy of $\mathrm{M}_{23} \mathrm{C}_{6}$ secondary carbides was 208 $\mathrm{kJ} / \mathrm{mol}$, which is in good agreement with what was found in a similar analysis carried out on the refractory alloy $45 \mathrm{Ni}-35 \mathrm{Cr}-\mathrm{Nb}$ [10] as well as with others research works $[10,16,17]$.

\section{Experimental}

Chemical composition of HP40-Nb heat resistant alloy is shown in Table 1.

Table 1 Chemical composition of centrifugally cast alloy HP40-Nb [wt \%].

\begin{tabular}{|c|c|c|c|c|c|c|c|c|}
\hline $\mathbf{C}$ & $\mathbf{S i}$ & $\mathbf{M n}$ & $\mathbf{C r}$ & $\mathbf{N i}$ & $\mathbf{N b}$ & $\mathbf{W}$ & $\mathbf{T i}$ & $\mathbf{F e}$ \\
\hline 0.57 & 2.73 & 0.76 & 23.7 & 37.6 & 1.26 & 0.19 & 0.07 & Balance \\
\hline
\end{tabular}

These alloys are produced as centrifugally cast tubes, with a $110 \mathrm{~mm}$ diameter and $11 \mathrm{~mm}$ wall thickness. From an as cast tube were cut several rings of $10 \mathrm{~mm}$-thick of which, in turn, 10x10x11 mm samples were obtained.

Aging heat treatment was made at 1073 and $1173 \mathrm{~K}$ using resistive furnaces in air atmosphere. For each temperature, aging times were of 1, 5, 15 and $30 \mathrm{~min}$, and 1, 3, 8, 16, 24 and $27 \mathrm{~h}$. After aging, each specimen was cooled in air. The aging heat treatments were all carried out in the same oven, which has a standardized and previously calibrated S-type thermocouple, which guarantees an accuracy of $1 \mathrm{~K}$. The measurement joint is adjacent to the sample to improve the quality of the measurement. Once each sample was introduced into the oven at the desired temperature, the aging time began to be counted when the thermocouple reached the previously set temperature. Metallographic preparation was done using different abrasive papers, each of them of decreasing particle size. Then, mechanical polishing was carried out with $1 \mu \mathrm{m}$ granulometry alumina. Since the high corrosion resistance of this alloys, electrolytic etching is recommended for optimal observation of it microstructure. For this purpose etching was done on each sample using $10 \% \mathrm{v} / \mathrm{v}$ $\mathrm{KOH}$ aqueous solution at an etching potential of $2 \mathrm{~V}$ for $14 \mathrm{~s}$. Etching parameters were adjusted to achieve an optimal contrast between matrix and $\mathrm{M}_{23} \mathrm{C}_{6}$ secondary carbides, and thus facilitating the later quantitative analysis. Optical micrographs were taken using a Leica DM ILM optical microscope with a DFC 295CCD camera. On each sample, 5 micrographs of 1000X magnification were taken for make the quantitative analysis. Finally, area fraction of secondary carbides was measured by image analysis using Image J software version 1.41 , developed by National Institutes of Health in the United States of America. The measurement method of this software is based on the contrast between particles and the background. In this way, the program calculates the ratio between the total area of the particles and the area of the micrograph, that is, the area fraction of the particles which, in the case of this work, are the secondary $\mathrm{M}_{23} \mathrm{C}_{6}$ carbides. In each optical micrograph, using Adobe Photoshop CC 2017 image processing software developed by Adobe Systems Incorporated in the United States of America, both the primary eutectic carbides and the 
background corresponding to the austenitic matrix were suppressed to improve the contrast and not to consider the measurement of primary carbides.

\section{Results and discussion}

As an example, in Fig. 1 to Fig. 4 it is shown, for each temperature, some optical micrographs for some aging times, which were used to measure the fraction in the area of secondary carbides oh HP40-Nb alloy.

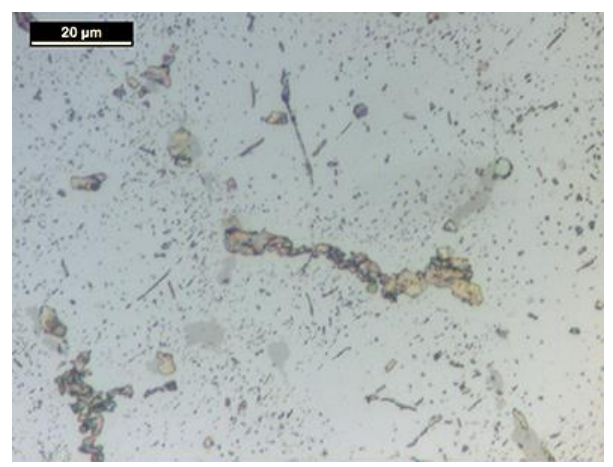

Fig. 1 Sample aged at $1073 \mathrm{~K}$ for $1 \mathrm{~h}$

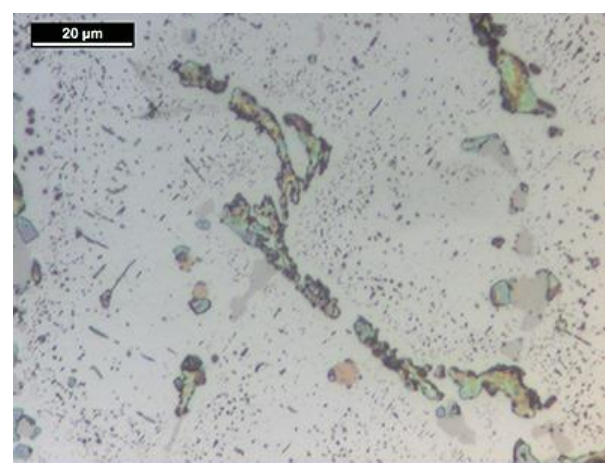

Fig. 3 Sample aged at $1173 \mathrm{~K}$ for $1 \mathrm{~h}$

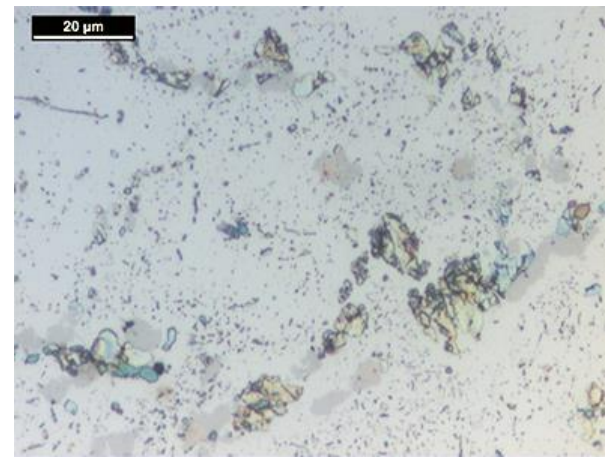

Fig. 2 Sample aged at $1073 \mathrm{~K}$ for $8 \mathrm{~h}$

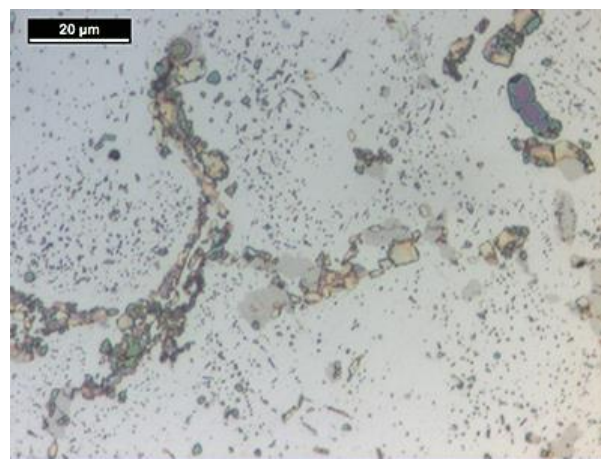

Fig. 4 Sample aged at $1173 \mathrm{~K}$ for $8 \mathrm{~h}$

The dendritic type microstructure can be appreciated, as well as the network of primary eutectic carbides rich in $\mathrm{Cr}$ and $\mathrm{Nb}$. In turn, secondary precipitation is observed, the amount of which as a function of time at the same temperature.

Applying JMAK model for an isothermal analysis, it can be obtained the transformed fraction of a certain phase, $f$, as a function of time. The model is exactly accurate for nucleation and growth reactions with linear growth, while it is a good approximation in cases of nucleation and growth with parabolic growth, i.e. as in the case of diffusion-controlled growth, if several hypotheses are met: random distribution of the precipitated phase, isotropic growth, uniform average growth rate throughout microstructure, the amount of a phase that can be transformed is independent of time, etc. [19-22]. In this case, secondary $\mathrm{M}_{23} \mathrm{C}_{6}$ precipitation is a thermally activated phenomenon controlled by diffusion.

The Avrami equation, relates the transformed fraction with aging time by:

$\mathrm{f}=1-\exp (-\mathrm{k} \cdot \mathrm{t})^{\mathrm{n}}$ 
where: $\mathrm{f}$ - area fraction of secondary carbides

$\mathrm{n}$ - Avrami exponent

$\mathrm{k}[\mathrm{s}-1]$ - pre-exponential factor

$\mathrm{t}[\mathrm{s}]$ - aging time

The pre-exponential factor, $\mathrm{k}$, is defined by an Arrhenius-type equation as:

$\mathrm{k}=\mathrm{k}_{0} \cdot \exp \left(-\frac{\mathrm{Q}}{\mathrm{R} \cdot \mathrm{T}}\right)$

where: $\mathrm{k}_{0}\left[\mathrm{~s}^{-1}\right]$ - constant

$\mathrm{Q}[\mathrm{kJ} / \mathrm{mol}]$ - activation energy of deformation

$\mathrm{R}[\mathrm{kJ} /(\mathrm{K} \cdot \mathrm{mol})]$ - universal gas constant

$\mathrm{T}[\mathrm{K}]$ - temperature

From the Avrami equation, it is possible to obtain a straight line function of slope $\mathrm{n}$ and intercept n. $\ln (\mathrm{k})$, which is plotted in Fig. 5, as a function of $\ln (\mathrm{t})$ for each aging temperature.

$\ln (-\ln (1-\mathrm{f}))=\mathrm{n} \cdot \ln (\mathrm{t})+\mathrm{n} \cdot \ln (\mathrm{k})$

For $1073 \mathrm{~K}$, the equation of the fitting function is:

$\ln (-\ln (1-\mathrm{f}))=0,88 \cdot \ln (\mathrm{t})-8,72$

In such a way, for $1173 \mathrm{~K}$, the equation is:

$\ln (-\ln (1-\mathrm{f}))=0,79 \cdot \ln (\mathrm{t})-6,73$

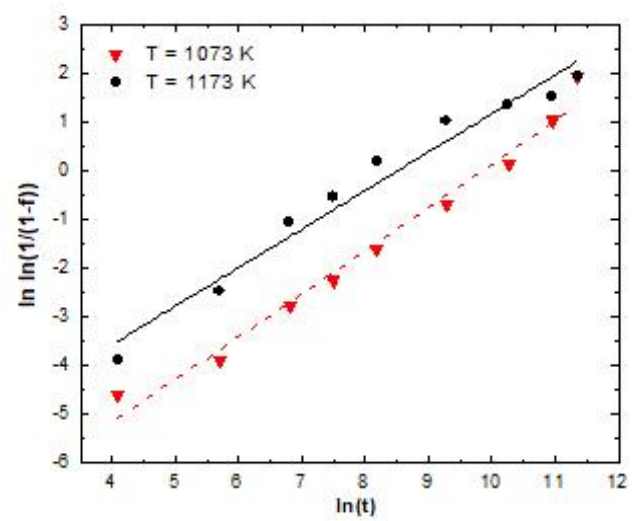

Fig. 5 Linear adjustment using the Avrami equation vs. aging time

The kinetic evolution of secondary carbides precipitation was characterized by occurs in a single step, which is in good agreement with other researches based on this kinetic model $[10,17]$. On the other hand, other authors have found in similar alloys that this reaction occurs, in two steps [16]. Once the kinetic parameters of the Avrami equation have been calculated for each aging temperature, it is possible to compare these results with the experimental data of the transformed fraction, as it is shown in Fig. 6. 


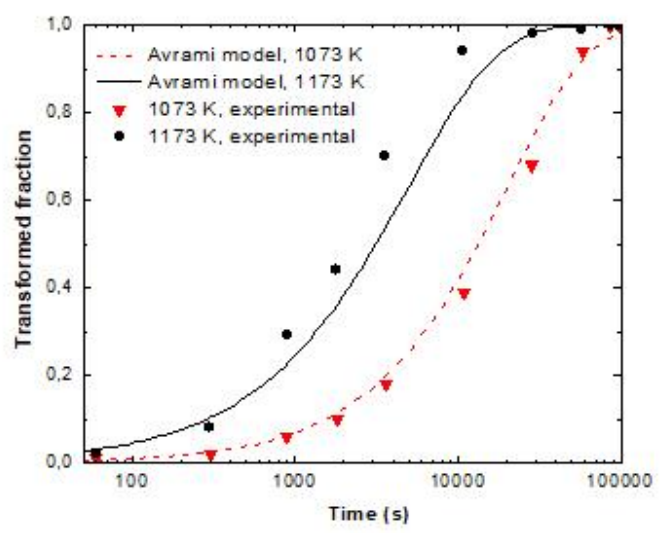

Fig. 6 Evolution of the experimental and calculated transformed fraction vs. aging time

Finally, the activation energy value of secondary precipitation, can be calculated by plotting n. $\ln (\mathrm{k})$ as a function of $(\text { R.T })^{-1}$ (see Fig. 7), resulting in a linear function defined by the slope $\mathrm{Q}$ and intercept $\ln \left(\mathrm{k}_{0}\right)$ and expressed with the following equation:

$\ln (\mathrm{k})=\ln \left(\mathrm{k}_{0}\right)-\frac{\mathrm{Q}}{\mathrm{R} . \mathrm{T}} \rightarrow \ln (\mathrm{k})=14,62-\frac{208}{\mathrm{R} . \mathrm{T}}$

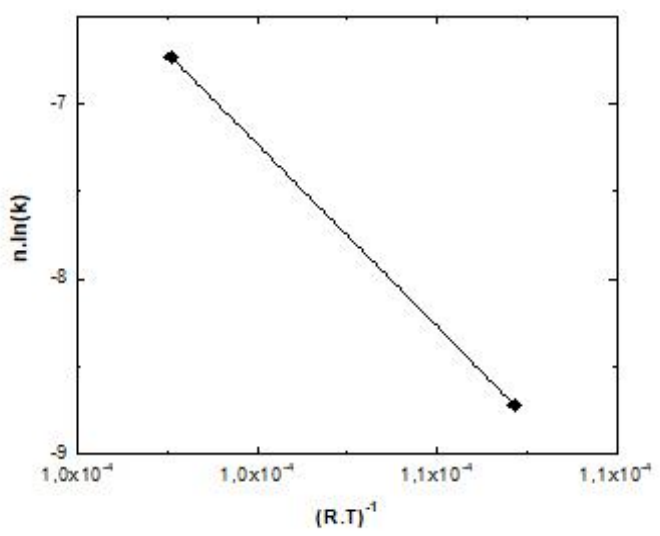

Fig. 7 Evolution of n.ln(k) vs. (R.T $)^{-1}$ in order to calculate the activation energy

In this way, the calculated activation energy $\mathrm{Q}$ of secondary $\mathrm{M}_{23} \mathrm{C}_{6}$ carbides precipitation is 208 $\mathrm{kJ} / \mathrm{mol}$ and $\mathrm{k}_{0}$ is $2,23 \times 10^{6} \mathrm{~s}^{-1}$. This value of $\mathrm{Q}$, allows to identify the mechanism that controls the precipitation of $\mathrm{Cr}$-rich $\mathrm{M}_{23} \mathrm{C}_{6}$ carbides. In this case, as it is a phenomenon assisted by diffusion, it is important to know the activation energy for self-diffusion of $\mathrm{C}$ and $\mathrm{Cr}$ atoms. In the case of $\mathrm{C}$, the self-diffusion energy in an austenitic matrix is of $142 \mathrm{~kJ} / \mathrm{mol}$ [23] while some authors have found by JMAL kinetic analysis, an activation energy of $213 \mathrm{~kJ} / \mathrm{mol}$ for a Fe-30.8Ni-26.6Cr alloy [16] and of $195 \mathrm{~kJ} / \mathrm{mol}$ for a $45 \mathrm{Ni}-35 \mathrm{Cr}-\mathrm{Nb}$ alloy [10]. As it can be seen, the calculated activation energy from JMAK model for a HP40-Nb heat resistant alloy would indicate that the mechanism 
that controls the secondary precipitation is the diffusion of the $\mathrm{Cr}$ atom through the austenitic matrix.

\section{Conclusions}

After applying the classic Johnson-Mehl-Avrami-Kolmogorov kinetic model in order to describe the secondary precipitation reaction in a HP40-Nb heat resistant alloys, several conclusions can be enumerated. First, it was found that the phenomenon occurs in a single stage, and the calculated activation energy of $\mathrm{M}_{23} \mathrm{C}_{6}$ secondary precipitation was $208 \mathrm{~kJ} / \mathrm{mol}$. Moreover, this value is comparable to that corresponding to the self-diffusion of $\mathrm{Cr}$ in an austenitic matrix of $\mathrm{Ni}-\mathrm{Cr}$ - $\mathrm{Fe}$ alloys. For this reason, the diffusion of $\mathrm{Cr}$ through the austenitic matrix would be the mechanism that controls the formation of $\mathrm{M}_{23} \mathrm{C}_{6}$-type secondary $\mathrm{Cr}$-rich carbides. Finally, the Avrami exponent value has very low variation with aging temperature.

\section{References}

[1] A. Picasso, C. Lanz, M. Sosa Lissarrague, A. Garófoli: Journal of Minerals and Materials Characterization and Engineering, Vol. 4, 2016, p. 48-61, https://doi.org/10.4236/jmmce.2016.41006

[2] R. Song, S. Wu: Engineering Failure Analysis, Vol. 88, 2018, p. 63-72, https://doi.org/10.1016/j.engfailanal.2018.01.002

[3] I. Sustaita Torres et al.: Materials Chemistry and Physics, Vol. 133, 2012, p. 1018-1023, https://doi.org/10.1016/j.matchemphys.2012.02.010

[4] A. Reihani, R. Derakhshandeh Haghighi: Engineering Failure Analysis, Vol. 52, 2015, p. 97-108, https://doi.org/10.1016/j.engfailanal.2015.03.005

[5] K. Buchaman, M. Kral, C. Bishop: Metallurgical and Materials Transactions A, Vol. 45, 2014, p. 3373-3385, https://doi.org/10.1007/s11661-014-2285-2

[6] M. Attarian, A. Karimi Taheri: Materials Science \& Engineering A, Vol. 659, 2016, p. 104-118, https://doi.org/10.1016/j.msea.2016.02.046

[7] MR. Andrade, C. Bolfarini, LAM. Ferreira, CD. Souza Filho, LHC. Bonazzi: Materials Science \& Engineering A, Vol. 636, 2015, p. 48-52, https://doi.org/10.1016/j.msea.2015.03.085

[8] CJ. Liu, Y. Chen: Materials and Design, Vol. 32, 2011, p. 2507-2512, https://doi.org/10.1016/j.matdes.2010.08.031

[9] MH. Sosa Lissarrague, S. Limandri, F. Prado, AC. Picasso: Metallography, Microstructure, and Analysis, Vol. 7, 2018, No. 3, p. 356-362, https://doi.org/10.1007/s13632-018-0448-Z

[10] MH. Sosa Lissarrague, A. Sepúlveda Buitrago, A. Picasso: Acta Metallurgica Slovaca, Vol. 25, 2019, No. 3, p. 180-185, https://doi.org/10.12776/ams.v25i3.1312

[11] J. Guo, T. Cao, C. Cheng, X. Meng, J. Zhao: Microscopy and Microanalysis, Vol. 24, 2018, p. 478-487, https://doi.org/10.1017/S1431927618015180

[12] AR. Andrade et al.: Materials Science \& Engineering A, Vol. 628, 2015, p. 176-180, https://doi.org/10.1016/j.msea.2015.01.049

[13]F. Tancret, J. Laigo, J. Furtado: Materials Science and Technology, Vol. 35, 2019, No. 3, p. 1924-1931, https://doi.org/10.1080/02670836.2019.1648371

[14]IA. Sustaita Torres, S. Haro Rodriguez, R. Colás: High Temperature Materials Proceedia, Vol. 37, 2018, No. 2, p.133-139, https://doi.org/10.1515/htmp-2016-0112

[15]R. Ortega Reyes, S. Haro Rodriguez, IA. Sustaita Torres, FA. Pérez González, R. Colás: Ingenierías, Vol. 22, 2019, No. 82, p. 22-32 
[16]G. Lothongkum, S. Ratanamahasakul, P. Wangyao: Acta Metallurgica Slovaca, Vol. 11, 2005, No. 1, p. 54-61

[17] A. Baltušnikas, I. Lukošiūtè, V. Makarevičius, R. Kriūkienè, A. Grybènas: Journal of Materials Engineering and Performance, Vol. 25, 2016, No. 5, p. 1945-1951, https://doi.org/10.1007/s11665-016-2002-y

[18]R. Badji et al.: Materials Chemistry and Physics, Vol. 148, 2014, p. 664-672, https://doi.org/10.1016/j.matchemphys.2014.08.032

[19] MJ. Starink: Journal of Materials Science, Vol. 36, 2001, No. 18, p. 4433-4441, https://doi.org/10.1023/A:1017974517877

[20]F. Liu, F. Sommer, C. Bos, EJ. Mittemeijer: International Materials Reviews, Vol. 52, 2007, No. 4, p. 193-212, https://doi.org/10.1179/174328007X160308

[21] J. Xu, F. Liu, S. Song, K. Zhang: Journal of non-Crystalline solids, Vol. 356, 2010, p. 1236-1245, https://doi.org/10.1016/j.jnoncrysol.2010.04.034

[22] ATW. Kempen, F. Sommer, EJ. Mittemeijer: Journal of Materials Science, Vol. 37, 2002, No. 7, p. 1321-1332, https://doi.org/10.1023/A:1014556109351

[23] W. Smith, J. Hashemi: Fundamentos de la ciencia e ingeniería de materiales, fifth ed., McGraw Hill, Mexico, 2014

\section{Acknowledgements}

This work was partially supported by IFISUR-CONICET, by Laboratorio de Metalurgia y Tecnología Mecánica of Departamento de Ingeniería (UNS) and Comisión de Investigaciones Cientificas de la Provincia de Buenos Aires (CICPBA). In addition, the authors wish to acknowledge to Consejo Interuniversitario Nacional (CIN) 